PressAcademia Procedia

4th Global Business Research Congress, May 24-25, 2018, Istanbul, Turkey.

\title{
THE IMPORTANCE OF ANALYTICAL INVESTIGATION TECHNIQUES IN INDEPENDENT AUDIT
}

\author{
DOI: 10.17261/Pressacademia.2018.912 \\ PAP- V.7-2018(65)-p.344-347
}

Oktay Tas ${ }^{1}$, Huseyin Mert ${ }^{2}$, Fatih Koc ${ }^{3}$, Ihsan Kamalak ${ }^{4}$

${ }^{1}$ Istanbul Technical University, Istanbul, Turkey.

tasokta@itu.edu.tr, ORCID: 0000-0002-7570-549X

${ }^{2}$ Okan University, Istanbul, Turkey.

huseyin.mert@okan.edu.tr, ORCID: 0000-0001-5391-7865

${ }^{3}$ Okan University, Istanbul, Turkey.

koc fatih@yahoo.com, ORCID: 0000-0002-0333-7456

${ }^{4}$ Okan University, Istanbul, Turkey.

ihsankamalak@hotmail.com, ORCID: 0000-0001-5391-7865

\section{To cite this document}

Tas, O., Mert, H., Koc, F., Kamalak, I. (2018). The importance of analytical investigation techniques in independent audit. PressAcademia Procedia (PAP), V.7, p.344-347.

Permemant link to this document: http://doi.org/10.17261/Pressacademia.2018.912

Copyright: Published by PressAcademia and limited licenced re-use rights only.

\section{ABSTRACT}

Purpose- The purpose of this study is to emphasize the importance of analytical review techniques under ISA 520 in the Independent Auditing process.

Methodology- Independent Auditing Standards will be referred to detailly. The impact of the Analytical Review Techniques on the Independent Audit Process will be determined.

Findings- It has been determined that Analytical Review Techniques have been used during the completion of Independent Audit's implementation of planning, material accuracy tests and audits

Conclusion- Analytical Investigation Techniques are techniques that are widely used in Independent Audit and are an effective audit technique.

Keywords: Audit standards, ISA 520, analytical investigation techniques.

JEL Codes: M40, M41, M42

\section{BAĞIMSIZ DENETIMDE ANALITIK INCELEME TEKNIKLERININ ÖNEMI}

\section{ÖZET}

Amaç- Bu çalışmanın amacı, Uluslararası Bağımsız Denetim Standartları'ndan olan BDS 520 Analitik Inceleme Tekniklerinin bağımsız denetim sürecindeki önemini vurgulamaktır.

Yöntem- Bağımsız Denetim Standartları ayrıntılı olarak incelenecektir. Analitik İnceleme Tekniklerinin Bağımsız Denetim sürecine etkisi tespit edilecektir.

Bulgular- Analitik İnceleme Tekniklerinin, Bağımsız Denetimin planlama, maddi doğruluk testleri uygulama ve denetimin tamamlanması aşamasında kullanıııı̆ı tespit edilmiştir.

Sonuç- Analitik İnceleme Teknikleri, Bağımsız Denetimde yaygın olarak kullanılan tekniklerden olup, etkin bir denetim tekniğidir.

Anahtar Kelimeler: Denetim standartları, BDS 520, analitik inceleme teknikleri.

JEL Kodları: M40, M41, M42

\section{GiRiş}

İs modellerinin karmaşıklaştığı ve global piyasaların daha çok birbirine entegre olduğu günümüz dünyasında muhasebe işlemleri de aynı oranda daha fazla karmaşıklaşmışıı. Denetim kanıtlarının elde edilmesinde ihtiyacına uygun şekilde kullanacağı denetim tekniklerinin seçiminde denetçi özgür bırakılmıştır. Fiziki inceleme, doğrulama, belge inceleme, yeniden hesaplama gibi denetim tekniklerinin yanı sıra sıklıkla kullanılan bir diğer teknik de doğrusal olmayan tutarsızlıkların, anormal sapmaların ortaya çıkartılmasında son derece etkili olan, denetimin kalitesini arttıran ve bu çalışmanın konusunu oluşturan analitik prosedürlerdir. 
Analitik prosedürleri tanımlamak için yaygın olarak kullanılan birkaç farklı terim bulunmaktadır. Bunlar: analitik denetim, analitik prosedürler, analitik inceleme, analitik delil veya analitik inceleme prosedürleridir. Analitik prosedürleri sadece denetim faaliyetinin bir tür unsuru olarak görmek yanlış olur. Analitik Prosedürler ayrıca, müşteri kabulü aşamasında denetim ücreti belirlenme safhasında, denetim yapılacak potansiyel sorunlu alanların tespitinde, test aşamasında hesap bakiyeleri ve işlemleri için test aşamasında ve genel olarak tüm inceleme safhasında denetçinin bilgi ve görüşüyle birlikte finansal tabloların güvenilirliğine ilişkin kanıt toplamada kullanılmaktadır.

\section{LITERATÜR INCELEMESI}

1987 yılında Amerika Birleşik Devletleri'ndeki Treadway Komisyonu, "Hileli mali raporlamanın tespiti için analitik gözden geçirme prosedürlerinin tam olarak uygulanmadığını bildirmektedir. (National Commission on Fraudulent Financial Reporting [NCFFR], 1987). Gerçek hile vakalarının incelenmesine dayanarak, Treadway Komisyonu, finansal tablo dolandırıcılıklarının, gerçekleştirilme şekline göre birbirine çok benzer olma eğiliminde olduğunu gözlemlemiştir. Çoğu hileli vaka, uygunsuz gelir tahakkuku, varlıkların şişirilmesi ve / veya masrafların uygunsuz şekilde giderleştirilmesiyle yapılmıştır. Genellikle, analitik prosedürler, fiili finansal tablo sonuçlarının, beklenilen finansal sonuçlarla karşılaştırılmasına yönelik sade veya kompleks bir tahmin modeli içermektedir. (Knapp, Knapp, 2001)

Analitik inceleme teknikleri finansal bilgilerin, finansal ve finansal olmayan bilgiler arasındaki ilişkilerin analiz edilmesi suretiyle değerlendirilmesi olarak tanımlanmaktadır. Analitik inceleme teknikleri denetim sürecinde farklı safhalarda, işletmenin, faaliyet koşullarının ve çevresiyle olan ilişkilerinin kavranması için risk değerleme yöntemi olarak, işletme yönetiminin sunduğu bilgi ve belgeler ile yaptığı açıklamalardaki önemli yanlışlık riskinin azaltılarak kabul edilebilir bir seviyeye indirilmesinde, detay testler yerine daha etkili veya etkin olduğunda bağımsız denetim teknikleri olarak ve bağımsız denetimin son aşamasında finansal tabloların genel olarak gözden geçirilmesi amacıyla kullanılır. (Kavut, Taş, Şavlı, 2009)

Analitik inceleme prosedürleri, denetimin planlanması, uygulanması ve tamamlanması aşamalarında kullanılabilen, uygulaması kolay ve pratik olan, olası tutarsızlık ve sapmaları ortaya çıkarmada yararlanılan, yapılacak denetim çalışmalarına yön veren bir denetim tekniğidir. Ayrıca analitik teknikler, olağan olmayan dalgalanmaların, hata ve hilelerin olabileceği hesap veya hesap gruplarına ve denetçinin dikkat etmesi gereken denetim alanlarına işaret ederek yapılacak testlerin sayısını azaltmada, zaman ve maliyet tasarrufu sağlamada oldukça etkin olarak kullanılmaktadır.

American Institute of Certified Public Accountants (AICPA)'nın yayınlamış olduğu 56 nolu denetim standardında (SAS:56) Analitik İnceleme Prosedürleri, "çeşitli finansal ve finansal olmayan veriler ile işletmenin kayıtları arasındaki anlamlı ilişkilerin incelenmesi ile elde edilen bilgilerin, denetçi tarafından geliştirilen beklentilere uyup uymadığına bakılması işlemlerine analitik inceleme prosedürleri adı verilmektedir." şeklinde tanımlanmıştır. (Bozkurt, s.151.)

Yine Kamu Gözetim Kurumu (KGK) tarafından 09/01/2014 tarihinde yayınlanan 28877 sayılı “Analitik Prosedürler (Bağımsız Denetim Standartları (BDS 520)) Hakkında Tebliğ" de analitik prosedürlerin işletmenin finansal bilgilerinin, önceki dönemlere ait işletme verileri ile işletmenin içinde yer aldığı sektör verileri ile, dönem başında planlanan bütçe gibi işletme yöneticilerinin veya denetçinin tahminleri ile ve finansal nitelikte olmayan bilgiler ile karşılaştırılmasına olanak sağladığı belirtilmiştir. (KGK, "Türkiye Denetim Standartları BDS 520 Analitik Prosedürler", s.8. Erişim Tarihi:05/03/2018.)

Bir denetçi farklı analitik inceleme teknikleri kullanabilir, bunlar, mevcut bilginin önceki yıllarla karşılaştırılması, denetçinin beklenti modeli ile karşılaştırılmasına ilaveten finansal bilginin, uygun finansal olmayan bilgiyle ilişkisinin çalışılması, diğer örgütsel birimlerdeki benzer bilgilerle karşılaştırılması, sektördeki diğer benzer bilgilerle karşılaştırılması şeklinde olabilir. Örneğin kamu denetimlerinde finansal verinin bütçe fiili karşılaştırılması önemlidir çünkü belediye bütçelerinin yasal bağlayıcılıkları vardır. KOBi'lerin denetiminde ise daha çok önceki yıllar karşılaştırması önemlilik arz etmektedir.

Denetçinin duruma göre kullanabileceği analitik prosedürler zaman içinde daha da gelişerek sadece beklenti modelinin dışına çıkarak farklı başlıklarla da incelenme yapılmasına olanak vermiştir. Literatürdeki analitik inceleme teknikleri şu şekildedir: i̇şletme verileri ile önceki yıllara ait benzer verilerin karşılaştırılması, işletme verileri ile işletme tarafından belirlenmiş bütçe ve tahminlerin karşılaştırılması, işletme verileri ile denetçi tarafından belirlenmiş beklenen sonuçların karşılaştırılması, işletme verileri ile sektör verilerinin karşılaştırılması, işletme verileri ile finansal olamayan verilerin ortaya koyduğu beklenen sonuçların karşılaştırılması.

KGK'nın yayınlamış olduğu BDS 520 standardına göre, analitik prosedürleri uygulamak için çeşitli yöntemlerden faydalanılabilir. Bu yöntemler basit mukayeselerin uygulanmasından, ileri istatistiki teknikleri kullanarak karmaşık analizler yapılmasına kadar çeşitlilik gösterir. Analitik inceleme tekniğinde yararlanılan bazı analiz tekniklerine aşağıda yer verilmiştir:

Yatay analiz ya da karşılaştırmalı tablolar analizi, en az iki dönemli mali tablo kalemlerindeki (aralarındaki anlamlı ilişkiler gözetilerek) artış ve azalışlarının tutar ve yüzde olarak hesaplandığı ve yorumlandığı analiz tekniğidir. Uygulaması kolay ve pratik olan, birden fazla dönemi kapsayan dinamik bir analiz tekniğidir.

Dikey analiz tekniği statik analiz tekniği olup, mali tablolarda yer alan hesap kalemi ve kümelerinin ağırlığını hesaplamaya ve yorumlamaya imkan verir. Bu yöntemde dönen varlıkların, kısa vadeli yabancı kaynakların, karların vb. tablo içindeki yüzdesi hesaplanır.

Trend analizi tekniği ise uzun dönemli bir analiz olup en az beş yıllık verilerin yıllar itibariyle seyrini (trendini) görmeye ve yorumlamaya olanak veren bir analiz tekniğidir. Orana analiz tekniği ise finansal tablo kalem ve kümelerin aralarındaki anlamlı ilişkiye göre bölünmesinden elde eidlen matematiksel ifadelerin yorumlanması süreci olarak tanımlanabilir. Bir işletmenin birbirini izleyen birkaç döneme ait bilanço ve gelir tablosu kalemlerinin baz olarak alınan bir yıldaki değere oranlanarak izlendiği dinamik bir analiz yöntemidir.

Analitik inceleme prosedürlerinin uygulanmasında bir diğer yöntemde ussallık testleridir. Burada finansal verilerle finansal olmayan verilerin aralarındaki mantıklı ilişki irdelenir. 
Ussallık testinde, beklenen değer, verilerle birlikte muhasebe bilgi sisteminden kısmen veya tamamen bağımsız olarak saptanır ve bu nedenle, böyle bir test yoluyla elde edilen kanıtlar, yalnızca bir muhasebe bilgi sistemi kullanılarak toplanan kanıtlardan daha güvenilir olabilir. Örneğin, bir nakliyecinin toplam yıllık gelirinin makullüğü, yıl boyunca taşınan toplam tonaj ve ton başına ortalama navlun oranı hesaplanarak tahmin edilebilir. (Koskivaara, 2004, s.337)

Her ne kadar biyolojik bir terim gibi görünse de Yapay Sinir Ağları regresyon analizindeki gibi önceden belirlenmiş bir modele gereksinim olmadan mevcut veriler arasındaki ilişkiyi öğrenen ve yeni bir durumla karşılaştığında genelleme yapabilen bir sistemdir. Ayrıca yöntem diğer analitik prosedürlerden farklı olarak doğrusal olmayan ilişkileri de tanımlayabilme özelliğine sahiptir. (Koskiavaara, s.191)

Ülkelere özgü işletme ve muhasebe kültürleri, denetçilerin uygulamada Analitik Prosedürleri kullanma biçimini etkiler. Örneğin, Amerika Birleşik Devletleri'nde, genel kabul görmüş denetim ilkeleri (GAAP) kapsamında bir denetimin planlanması ve genel gözden geçirme safhalarında Analitik prosedürlerinin kullanılması zorunludur. Ayrıca AICPA'nin belirlemiş olduğu koşula göre, analitik prosedür uygulanacak olan beklenti modelini yaratırken denetçiye, bu modeli yaratan koşulları spesifik bir biçimde belgeleme zorunluluğu da getirmektedir. (AICPA 2002a).

\section{ANALiTiK INCELEME TEKNIKLERIYLE ŞiRKETLERDE KARŞILAŞABILECEK ÖRNEKLER}

Analitik İnceleme Yapılması, aşağıda belirtilen hususlarda denetçiye yardımcı olur:

- $\quad$ Bir petrol firmasında, petrolün tavan ve taban fiyatları sektör tarafından belirlenmektedir. Eğer petrol şirketine ait Brüt Kar Marjı, sektör ortalamasının çok üstünde veya altında gerçekleşiyorsa, alış fiyatındaki veya satış fiyatından yola çıkarak ortaya çıkarılabilir.

- Bir firmada çalışan işçi sayısı ile bu işçilere sağlanan ekmek sayısındaki ilişki, klasik denetim yöntemlerinden ayrışarak incelenebilir. Klasik denetim yönteminde, sağlanan ekmek tutarının faturaya bağlı olup, olmadığı, kayıtlarda uygun şekilde giderleştirilip, giderleştirilmediği incelenirken, Analitik İnceleme Teknikleriyle sağlanan ekmek ve personel sayısı arasındaki korelasyonun tutarlı olup olmadığına bakılabilir.

- Bir şirketin stokları için ambar kapasitesi 10 Ton iken, denetçinin yaptığı çalışmalarda olumlu veya olumsuz farkların olması, açıklamalar gerektirir.

- Stok Devir Hızı, Alacak Devir Hızı yöntemleriyle alacak satış ilişkileri ve stoklarda olan gerçek kısmın ortaya çıkarılmasına yardımcı olur. Bu da ussallık testleri yöntemiyle ortaya çıkarılır.

- Randıman testleri (girdi/çıktı), kapasite raporları kullanılarak fire, olması gereken fire veya olması gerekenden fazla yazılan giderler bu tekniklerle denetçiye yardımcı olabilir.

- Kısa ve uzun vadeli borç yapısıyla birlikte, işletmenin likiditesi, borç ödeyebilme kabiliyeti ve çalışma sermayesinin yeterliliği tespit edilebilir.

- Bütçe verileriyle gerçekleştirmeleri karşılaştırmak, denetçi için önemli bulgulardandır. Denetçi burada, bütçeyi uygulayacak olan işletme personelinin bütçe hedeflerinin yakalayamama kaygılarından dolayı bütçeyi değiştirmiş olabilme ihtimalini göz önünde bulundurmalıdır.

- Ulaşım işletmelerinde doluluk oranının ortalama gelirinin tahmin edilmesi veya işçi sayısından ve saat ücretlerinin işletme maliyetleri ve üretim miktarının tahmin edilmesinde teknikler önemli olarak kullanılmaktadır.

\section{SONUC}

Bu çalışmada bağımsız denetimin planlanması, maddi doğruluk testleri ve tamamlanması aşamasında analitik inceleme teknikleri önemli bir yere haizdir. Günümüzde bu teknikleri etkin olarak kullanabilen denetçiler sayesinde denetim faaliyetlerinin yürütülmesinde yeni bir evreye geçilmiştir. Bağımsız denetimin yürütülmesi ve raporlanması esnasındaki kafa karışıklı̆ı finansal ve finansal olmayan verilerin denetim riski ve kontrol riski göz önünde bulundurularak tekniklerin hangi aşamalarda kullanılacağı post modern yaklaşımı ile nitel araştırma yöntemleri kullanılarak toplum, şirketler, denetçiler ve yatıımcıların gereksinimlerine göre tartışılmıştır. Ancak nihai durum göstermektedir ki, artık bağımsız denetim sırf klasik yöntemlerle fatura ve gider eşleştirmesinden ibaret olmadığını ortaya koymaktadır.

Analitik İnceleme Prosedürleri, hedeflerin oluşturulması aşamasıyla başlayan ve planlama aşamasında uygun prosedürün belirlenmesi süreciyle devam eden bir süreçtir. Özellikle uygulama aşamasında uygun ve ilgili verinin kullanımı hesaplamanın doğru yapııması aşamasında azami öneme haizdir. Çünkü planlama ve uygulama aşamaları doğru olarak gerçekleştirilmediği takdirde sonuçların analiz edilmesi gecikebilir veya daha da olumsuz olarak yanlış verilerle yanlış sonuçlara gidilebilecektir. Bu durumda nihai verilecek karar tüm bilgi kullanııılarını yanılııı nitelikte olabilir, denetçinin itibarına gölge düşürebilir. Bu gibi sonuçlara mahal vermemek için hedefin oluşturulması aşaması ile başlayan süreç sistematik bir şekilde her bir bağımsız denetim için gözden geçirilmelidir.

Analitik İnceleme Prosedürleri, gelecekte yerini finansal olmayan bilgileri de içeren daha geniş tabanlı çalışmalara bırakacaktır. Bu değişim sadece işletmeleri değil, muhasebe meslek mensupları ile muhasebe akademisyenlerini de gelişen teknikler çerçevesinde kişisel gelişime ve yeni yöntemler aramaya sevk edeceği görülmektedir. 


\section{KAYNAKLAR}

Bozkurt, N. (2014). Muhasebe denetimi. İstanbul: Alfa Yayınları.

Knapp, C. A., Knapp, M. A. (2001). The effects of experience and explicit fraud risk assessment in detecting fraud with analytical procedures. Accounting, Organizations and Society, 2001, vol. 26, issue 1, 25-37.

Kavut, L., Taş, O., Şavlı, T. (2009). Uluslararası denetim standartları kapsamında bağımsız denetim. ISMMMO, 2009

KGK. Türkiye denetim standartları BDS 520 analitik prosedürler.

Koskivaara, E. (2004). Artificial neural networks in analytical review procedures. Managerial Auditing Journal, 19(2), $2004:$ 192 s.191-223.

Koskivaara, E. (2007). Integrating analytical procedures into the continuous audit environment. Journal of Information Systems and Technology Management, Vol. 3, No. 3, 2007, p. 331-346. 